\title{
Descrição e construção do Questionário Senior de Atividades Físicas para Idosos (QSAP)
}

\author{
Paulo de Tarso Veras Farinatti ${ }^{1}$, Jacques Henri-Paul Vanfraechem ${ }^{2}$ e Daniel Clemen ${ }^{2}$
}

\section{RESUMO}

A avaliação da autonomia do idoso focaliza-se habitualmente nas atividades desempenhadas ou na aptitude funcional. Raros são os instrumentos que levam em conta ambos os aspectos. Este estudo descreve o desenvolvimento de uma das partes de um sistema de avaliação que tenta cobrir esta lacuna - o Questionário Senior de Atividades Físicas (QSAP). Trata-se de uma entrevista em quatro partes, quantificando as necessidades para uma vida autônoma em termos de força (FO) e de produção de energia para o trabalho (PA). A Parte I considera as atividades cotidianas no domicílio, profissionais e de tempo livre. A Parte II avalia o contexto de vida do entrevistado. A Parte III aprecia as dificuldades para tarefas cotidianas e os sentimentos quanto às atividades que se gostaria de fazer. A Parte IV considera o ponto de vista do entrevistador. Obtêm-se para cada parte dois índices parciais TOT (FO) e TOT (PA). Os índices gerais são três: ITOT (FO), ITOT (PA) e IAE. Aplicaram-se 164 questionários a belgas de 60 a 90 anos ( $\overline{\mathrm{X}}=69,9 \pm 7,12)$. Determinou-se o IAE por: a) análise de componentes principais para os índices TOT; b) cálculo dos escores fatoriais referentes ao primeiro fator; $\mathrm{c}$ ) regressão múltipla entre os escores fatoriais e os ITOT; d) transformação dos resultados da regressão em unidades correspondentes à idade cronológica. Testaram-se a representatividade e a estabilidade do IAE por: a) comparação aos resultados parciais do questionário; b) comparação com a idade cronológica; c) validação cruzada para 20 indivíduos ( $\overline{\mathrm{X}}$ $=67,40 \pm 5,39$ anos). Resultados: a) o IAE representa bem o conjunto das questões do QSAP; b) as necessidades para uma vida autônoma, traduzidas pelo IAE, guardam correlação inversa moderada com a idade; c) a equação de regressão pare-

1. Instituto de Educação Física e Desportos, Universidade do Estado do Rio de Janeiro, Rio de Janeiro, RJ, Brasil,

2. Laboratoire de l'Effort/Institut Supérieur d'Education Physique et Kinésithérapie, Université Libre de Bruxelles, Bruxelas, Bélgica.

\section{Endereço para correspondência:}

Correspondência concernente ao processo de publicação deve ser enviada a Paulo Farinatti. Endereço: Laboratoire de l'Effort-ISEPK, Université Libre de Bruxelles, Av. Paul Heger 28 CPI 168, B-1000, Bruxelles, Belgique. E-mail: JRVANFRA@ULB.AC.BE. Fax: 00322-6503114. ce ser estável. Conclui-se que o QSAP como um todo - e o IAE especificamente - têm boa validade de conteúdo. Recomenda-se, contudo, a verificação posterior da pertinência e da reprodutibilidade do método, antes da generalização de sua aplicação.

Palavras-chave: Idosos. Questionário. Autonomia. Atividade física. Avaliação. Validade. Análise fatorial. Regressão múltipla.

\section{ABSTRACT \\ Description and development of the senior physical activity questionnaire (QSAP)}

Elderly autonomy is mainly evaluated by activities of daily living or functional fitness instruments. Both aspects are scarcely associated. This study describes the development of the Senior Physical Activity Questionnaire (QSAP), which is part of an evaluation system that takes into account the interaction of these factors. It is a four part interview, quantifying elderly needs in terms of strength (FO) and energy production (PA). Part I considers domestic, professional and freetime activities of daily living. Part II evaluates the living context of the subject. Part III is concerned with the difficulties for the activities of daily living, and with the subject's feelings aroused from not practising activities he longs for. Part IV regards the interviewer's point of view about the three former parts. Two partial indices are obtained for each part of the questionnaire: TOT (FO) and TOT (PA). Three general indices are calculated: ITOT (FO), ITOT (PA) and IAE. Questionnaires were applied to 164 Belgians of both sexes, from 60 to 90 years $(\bar{X}=69.9 \pm 7.12)$. The IAE was defined by: a) principal component analysis for TOT indices; $b$ ) first factor scores determination; c) multiple regression between factor scores and ITOT indices; d) standardisation of the regression results by the chronological age. IAE's stability and content validity was tested by: a) comparison with QSAP partial indices; b) comparison with subjects' chronological age; c) cross-validation for a sample of 20 subjects ( $\bar{X}=67.40 \pm$ 5.39 years). Results suggest that: a) the IAE is representative of the QSAP items; $b$ ) physical autonomy needs, as quantified by IAE, have a inverse correlation (though poor) with age; c) the regression equation is stable. It is concluded that 
the QSAC as a whole, and specifically the IAE, show good levels of content validity. However, further studies are recommended to assess the pertinence (criterion and structure related) and the reproducibility of the method, before generalising its application.

Key words: Elderly. Questionnaire. Autonomy. Physical activity. Evaluation. Validity. Factor analysis. Multiple regression.

\section{INTRODUÇÃO}

Muitos estudos dedicam-se à avaliação da autonomia da pessoa idosa ${ }^{1-7}$. As possibilidades de manutenção de vida independente são tidas como essenciais para a qualidade de vida dessa população. Contudo, a maior parte das iniciativas nesse sentido adota uma perspectiva ora negativa, ora exclusivista. A perspectiva negativa procura avaliar a autonomia por exclusão: tenta-se identificar possíveis problemas ou obstáculos para a vida autônoma ${ }^{8}$. Na ausência desses obstáculos, considera-se o indivíduo como autônomo. Por exclusivismo entendemos a tendência de avaliar a autonomia a partir das atividades realizadas, ou a partir da condição física, pura e simplesmente. Assim, os chamados sistemas de avaliação das atividades da vida cotidiana (questionários ADL, IADL ou AADL) enfatizam as atividades ${ }^{1,9,10}$, enquanto os sistemas de determinação da aptitude funcional apreciam a normalidade das condições físicas individuais ${ }^{11-16}$.

Recentemente, desenvolvemos um sistema de avaliação mais amplo, que tenta levar em consideração ambos os aspectos mencionados (o Sistema Senior de Avaliação da Autonomia de Ação de Idosos). O sistema é composto de dois instrumentos. O primeiro consiste de um questionário (Questionário Senior de Atividades Físicas - QSAP) sobre as atividades físicas, vistas segundo três dimensões distintas: a) $O$ que o indivíduo faz; b) o que o indivíduo deve fazer; c) o que o indivíduo deseja fazer. Este questionário permite definir índices representativos das necessidades pessoais, no que diz respeito a aspectos previamente selecionados da aptidão física. Uma revisão da literatura permitiu-nos selecionar a capacidade de produzir energia útil para o trabalho (PA) e a força de membros superiores (FO) como aspectos a avaliar. Essas necessidades estariam associadas a um índice geral, representando as ações das quais a autonomia exprimida do indivíduo dependeria. O segundo instrumento é um teste de campo (Teste Senior de 'Caminhar e Transportar'), cujo objetivo é a avaliação da aptidão física. Não se pretende que seus resultados sejam utilizados como medidas precisas da força ou da capacidade aeróbia, mas que reflitam o comportamento conjunto destas variáveis dentro de uma ótica funcional. O teste de campo permite, então, calcular índices representativos do potencial de realização das tarefas que dependem destes aspectos da aptidão. Em outras palavras, estes índices refletem a autonomia potencial do indivíduo. Do cruzamento das informações obtidas pelo questionário e pelo teste de campo, estabelece-se uma razão autonomia potencial-autonomia exprimida, que foi denominada Índice Senior da Autonomia de Ação.

Este estudo refere-se especificamente ao QSAP. Seus objetivos são: a) descrever o processo de construção teórica psicométrica do questionário; b) descrever o processo de desenvolvimento de um índice geral representativo do questionário como um todo, bem como verificar sua pertinência e estabilidade.

\section{DESCRIÇÃO DO QUESTIONÁRIO SENIOR DE ATIVIDADES FÍSICAS}

O QSAP encontra-se no Anexo 1. Apesar de traduzido, é bom ressaltar que este estudo utilizou a versão original, em francês. Antes de passar a descrever as estratégias para verificar sua pertinência e fidedignidade, julgamos útil apresentar suas características gerais, em relação à natureza das questões e ao sistema de cotação. Dividimos esta apresentação em duas partes: contrução teórica e contrução psicométrica.

\section{1) Construção teórica}

O QSAP é composto de 17 items distribuidos em 4 partes, a saber: Parte I - O que o entrevistado faz, Parte II - O que o entrevistado deve fazer, Parte III - O que o entrevistado deseja fazer, Parte IV - Ponto de vista do entrevistador. Conforme recomendado pela maior parte dos estudos com ido$\operatorname{sos}^{2,17}$, a forma de aplicação do questionário é a entrevista pessoal. Foi adotado como sistema de administração o modelo 'Folhas do Entrevistador-Folhas do Entrevistado'. Neste modelo, o entrevistado não recebe o questionário integral, mas apenas folhas de resposta nas quais encontra as informações necessárias à escolha das opções de respostas. A matriz do questionário é preenchida pelo entrevistador. Tal sistema é adotado por outros questionários concebidos para populações idosas, como o Yale Physical Activity Survey for Older Adults ${ }^{18}$ ou o Frail Elderly Functional Assessment Questionnaire $^{10}$.

A Primeira Parte (itens 1 a 3) corresponde às necessidades ligadas ao que o entrevistado faz em sua vida cotidiana. Ela é dividida em três domínios: as Atividades no Domicílio, as Atividades Profissionais e as Atividades de Tempo Livre. Os itens da Parte I relacionam-se com a frequiência e a duração de diversas ocupações em cada um destes domínios. As ocupações foram selecionadas com base em três grandes surveys, dois levados a cabo nos Estados Unidos e um na França - o National Health Interview Survey versão $1985^{19}$, o Nurses' Health Study II ${ }^{20}$ e o projeto PAQUID (o Quid des Personnes Agées $)^{21}$ - assim como em um extenso Compêndio de Atividades Físicas publicado por Ainsworth et al..$^{22}$.

A Segunda Parte (itens 4 a 12) refere-se ao contexto de vida do entrevistado. Seu objetivo é quantificar as necessidades impostas pelas condições ambientais (no que toca aos 
aspectos da aptidão física selecionados). As questões 4 a 6 consideram explicitamente as atividades para cuja execução deve-se caminhar ou subir escadas, aspectos da mobilidade pessoal universalmente reconhecidos ${ }^{4,20,23-29}$. Os itens 7 a 9 pedem ao entrevistado que classifique o grau de adaptação de sua moradia e de seu meio ambiente físico às suas capacidades, e às capacidades das pessoas idosas em geral. É evidente que existe uma relação entre o meio-ambiente físico e as possibilidades de expressão da autonomia de ação. Muitos estudos examinam essa relação, observando os efeitos da modificação das condições ambientais sobre a aptidão funcional, a adaptação dos idosos a essas modificações ou as adaptações impostas por alterações na aptidão física ${ }^{7,30-32}$. O item 10 pede ao entrevistado que classifique o nível de trabalho físico associado a seu cotidiano. A classificação é feita com o auxílio de uma escala progressiva de intensidade (muito leve, leve, média, pesada, muito pesada). A utilização de escalas progressivas para essa avaliação é bem difundida e tem boa validade ${ }^{5,10,24,33-35}$. Adotou-se um estilo misto, no qual a subjetividade da classificação foi diminuída pela inclusão de definições do tipo de atividades que correspondem à classificação da intensidade. Esse modelo de questão foi validado pelo Stockholm-MUSIC 1 Study ${ }^{36}$, cujo questionário propõe um item similar. A elaboração do item 11 também foi influenciada pelo Stockholm-MUSIC 1 Study ${ }^{36,37}$ : adaptaramse duas questões do questionário aplicado por aquele estudo, com referência à manipulação de objetos. $\mathrm{O}$ último item dessa parte do questionário é o 12 . Ele retoma o problema do deslocamento, de forma mais direta e específica que o item 8: perguntam-se quais são os meios de transporte mais utilizados pelo entrevistado. Esse tipo de questão é comum em instrumentos que quantificam as atividades físicas, como o Questionário de Baecke Modificado ${ }^{26}$ ou o Tecumseh Occupational Activity Questionnaire ${ }^{38}$.

A Terceira Parte do questionário inclui os itens 13 e 14. Ela é dedicada às dificuldades percebidas pelo entrevistado durante a realização das atividades físicas do dia-a-dia, e aos sentimentos associados às atividades que ele gostaria de começar a fazer ou retomar. A estrutura do item 13 aproximase muito das características da maior parte dos instrumentos de avaliação de autonomia, cuja perspectiva é negativa: a auto-avaliação é direcionada à percepção das dificuldades ressentidas quando da execução de certas atividades. A diferença, aqui, é que se valoriza especialmente a natureza subjetiva do que se considera uma dificuldade. Por exemplo, se o indivíduo não pratica desporto, a dificuldade percebida por este tipo de atividade pode ser muito leve. Por outro lado, um indivíduo desportista que começa a aperceber-se do declínio de seu desempenho, pode atribuir às suas dificuldades uma classificação média ou mesmo elevada. Esta valorização da subjetividade dos julgamentos justifica-se pelos objetivos desta parte do questionário. Não podemos esquecer que as informações referem-se ao que o entrevistado deseja fa- zer. A dificuldade física real é menos importante que as consequiências para a realização das atividades às quais o idoso se propõe. O item 14 procura introduzir uma ótica diferente da do item 13. As atividades que o indivíduo gostaria de fazer, mas que não faz, assim como a magnitude do sentimento de privação decorrente deste fato, são considerados como elementos importantes para a definição das necessidades associadas à autonomia de ação. Em outras palavras, em nosso sistema a autonomia de ação depende também dos objetivos vitais, dos projetos de vida, e não somente do contexto atual. Assim, um idoso sedentário e feliz de o ser deve ser considerado tão ou mais autônomo que aquele que faz diversas atividades em seu cotidiano, mas que se sente insatisfeito em função das atividades que não realiza. Não pudemos localizar instrumentos de avaliação da autonomia que tenham proposto um item similar.

A Quarta Parte do questionário (itens 15 a 17) é preenchida pelo entrevistador. O objetivo é minorar o grau de subjetividade do julgamento do entrevistado, principalmente nas questões em que menciona o nível de esforço físico associado ao cotidiano. Visto que esse tipo de questão é frequientemente comparativo, um indivíduo que vive em uma comunidade cuja rotina é marcada pela atividade árdua pode estimar que as atividades de seu dia-a-dia sejam leves. Essas mesmas atividades podem ser classificadas como pesadas por outro indivíduo vivendo em um meio sedentário. Da mesma forma, as classificações com respeito às condições do domicílio, dos transportes coletivos ou da vizinhança podem ser influenciadas pela realidade à qual o entrevistado está habituado. Parte-se do princípio de que o entrevistador pode contribuir, com seu julgamento, para completar as informações fornecidas pelo entrevistado, já que suas experiências não são as mesmas que a deste último.

\section{2) Construção psicométrica}

A elaboração do sistema de pontuação do QSAP englobou três etapas: a) a cotação dos itens do questionário em termos de intensidade; b) a cotação do conjunto de cada parte e a equivalência dos pontos obtidos em relação ao total de pontos possíveis; c) a definição dos índices gerais do questionário.

Para determinar as intensidades das atividades quanto à capacidade de produção de energia útil para o trabalho, foi adotado como referência o Compêndio de Atividades Físicas de Ainsworth et al. ${ }^{22}$. No entanto, a estrutura do questionário pedia que atribuíssemos categorias de intensidade aos valores absolutos associados às diversas atividades. Tratava-se assim de definir os valores em METs, que corresponderiam a cada uma de nossas categorias. Muitos estudos valem-se desse tipo de categorização ${ }^{20,35,38-41}$. Apesar de certa discordância entre as proposições, constatamos que as classificações tocam em pontos comuns. Por exemplo, as atividades classificadas como leves ou muito leves são associadas a intensida- 
des próximas de 3 ou 4 METs. Da mesma forma, tarefas tidas como pesadas ou muito pesadas demandam consumo calórico da ordem de 6 a 7 METs. Decidiu-se, assim, trabalhar com três categorias, determinadas a partir da classificação absoluta de Ainsworth et al. ${ }^{22}$ : o nível 0 corresponde às atividades de intensidade de 1 a 2 METS, o nível 1 abrange aquelas entre 2 e 4 METs, o nível 2 engloba intensidades de 4,1 a 6 METs e o nível 3 refere-se a gastos calóricos que ultrapassem os 6 METs.

A determinação das categorias de intensidade para a força foi mais arbitrária. Em comparação ao gasto calórico, há poucos trabalhos consagrados à classificação das atividades físicas em termos de tensão muscular. Para definir uma categorização adequada a nossos objetivos, baseamo-nos em alguns resultados do MUSIC I Study Group ${ }^{36,37}$ e em estudos epidemiológicos visando a avaliação de riscos de problemas músculo-esqueléticos devido à manipulação de cargas pesadas $^{42,43}$. A intensidade das atividades para a aplicação da força de preensão manual foi estabelecida como segue: nível 0 - peso de 0kg (mãos livres), nível 1 - pesos de até $5 \mathrm{~kg}$, nível 2 - pesos de 6 a $15 \mathrm{~kg}$, nível 3 - pesos de mais de $15 \mathrm{~kg}$.

A seguir, definiu-se o sistema de cotação de cada parte do questionário. Na Parte I os pontos são obtidos pelo produto entre a frequiência, a duração e a categoria de intensidade associada a cada atividade. Esse procedimento é adotado pela quase totalidade dos questionários ou inventários quantificando as atividades físicas. A diferença reside em que, na maior parte dos instrumentos, a freqüência, a duração e a intensidade são consideradas em termos absolutos (dias por semana, minutos/horas e gasto calórico), já que objetivam medir o consumo energético cotidiano. Preferimos trabalhar com outro sistema, mais de acordo com nossos objetivos: ainda que possamos traçar um paralelo entre o gasto energético total e a intensidade máxima das atividades do dia-adia, esses dados representam coisas diferentes. O gasto calórico total de um indivíduo que trabalha o dia inteiro em atividades de intensidade média pode ser mais elevado que o de outro que trabalha algumas horas em atividades de intensidade superior. Mas, quando se trata de avaliar as necessidades em termos de força e de produção de energia para a realização destas tarefas, o somatório total do consumo energético é menos importante que a intensidade das atividades consideradas isoladamente. Além disso, a precisão exigida pelos questionários sobre os gastos calóricos não é mister em nosso caso: uma classificação superficial responde plenamente às necessidades de nosso instrumento, ao mesmo tempo em que diminui a variabilidade das respostas. No sistema de cotação da Parte I, além da categorização da intensidade das atividades, sua duração e freqüência foram pontuadas de acordo com as opções escolhidas nas Folhas de Respostas: a) $=1, \mathrm{~b})=2, \mathrm{c})=3, \mathrm{~d})=3$, e) $=0$. Essas opções representam freqüências e durações de um amplo espectro (ver Anexo 1). Para obter a cotação referente às Atividades no Domicílio, adicionam-se os pontos das seis atividades mais pontuadas. Para as Atividades Profissionais, considera-se apenas a atividade mais intensa. Finalmente, para as Atividades de Tempo Livre, utilizam-se as duas atividades mais pontuadas. A limitação do número de atividades e a associação da duração e da freqüência a valores ordinais de 0 a 5 permitiram-nos fazer uma equivalência entre as três dimensões desta parte do questionário, em função do máximo de pontos que poderiam ser obtidos. Essa equivalência era necessária porque, para calcular os pontos concernentes ao que $o$ entrevistado faz, não queríamos atribuir uma importância maior a nenhuma das dimensões. A somação simples dos pontos de cada dimensão definiria uma hierarquização, visto que o número de atividades consideradas por cada uma é diferente $(6,1$ e 2$)$. A equivalência foi feita pela técnica do mínimo múltiplo comum (MMC). O total de pontos para a potência aeróbia ( $\sum$ Pontos (I) PA) e para a força ( $\sum$ Pontos (I) FO) é, então, obtido pelo somatório dos pontos corrigidos pelo MMC, para cada dimensão (ver Anexo 1).

A cotação da Parte II obedeceu a outros critérios. As respostas aos itens foram colocadas em ordem crescente, de 0 a 4. A cada item corresponde uma cotação obtida pelo produto entre o valor da resposta e o código de intensidade atribuído às atividades em questão. A exceção é o item 12, cuja cotação advém da soma dos pontos das duas primeiras opções de transporte escolhidas. O total de pontos para a potência aeróbia ( $\sum$ Pontos (II) PA) e para a força ( $\sum$ Pontos (II) FO) é calculado pelo somatório dos pontos obtidos em cada item.

Na Parte III, os pontos de cada subitem do item 13 são obtidos pelo produto entre o grau de dificuldade escolhido e a categoria de potência aeróbia ou força correspondente. A cotação final desse item é a soma de todos os pontos intermediários. O item 14 é calculado da mesma forma. Inicialmente, determinam-se as categorias PA e FO para a atividade mais intensa mencionada no subitem (14a) e, a seguir, multiplicam-se estes valores pelo valor da opção escolhida para os sentimentos associados à 'não-prática' dessa atividade. Partimos do princípio que, quão mais negativos esses sentimentos, maior o desejo do indivíduo de retomar ou iniciar as atividades citadas, o que repercutiria sobre suas necessidades físicas. $\mathrm{O}$ total de pontos para a potência aeróbia ( $\sum$ Pontos (III) PA) e para a força ( $\sum$ Pontos (III) FO) é obtido pelo somatório dos pontos dos dois itens.

Na Parte IV os códigos atribuídos à potência aeróbia e à força são inteiramente arbitrários, o que não influencia significativamente a lógica da cotação. De fato, o que importa é a classificação escolhida: se ela é elevada, as necessidades associadas também o serão. Nos itens 15 e 16, os pontos são obtidos pelo produto entre a opção selecionada e os códigos PA e FO. No item 17, os pontos correspondem diretamente à opção. O somatório dos pontos dos itens resulta nos valores totais para potência aeróbia ( $\sum$ Pontos (IV) PA) e força $\left(\sum\right.$ Pontos (IV) FO). 
A fim de comparar os resultados das partes do questionário entre si, imputamos aos totais respectivos uma unidade de mesma proporção. Considerando a natureza ordinal dos resultados de muitos itens, escolhemos reduzir todos os totais à percentagem de pontos obtidos, calculados a partir do máximo possível de pontos em cada parte. Com isso, o $\sum$ Pontos PA e o $\sum$ Pontos FO foram divididos por 1.440 (Parte I), 71 (Parte II), 105 (Parte III) e 12 (Parte IV). Os índices resultantes, considerados até a terceira casa decimal, foram denominados TOT I (PA/FO), TOT II (PA/FO), TOT III (PA/ FO), TOT IV (PA/FO). A comparação dos índices TOT pode fornecer informações interessantes: por exemplo, se os índices TOT III são significativamente superiores aos TOT I, poderia deduzir-se que o indivíduo encontra-se em um estado sedentário com o qual não se conforma. Por outro lado, divergências entre os índices TOT II e TOT IV podem sugerir que os julgamentos do entrevistado foram influenciados por seu contexto de vida e que faltam-lhe parâmetros de referência para um julgamento mais objetivo. Poderíamos ainda descrever artefatos equivalentes em face de dispersões entre os índices TOT de uma mesma parte do questionário, relativos à força e à potência aeróbia.

A última etapa da construção psicométrica do QSAP foi a definição de seus índices gerais. Além dos totais parciais referentes às partes do questionário, foram estabelecidos os índices ITOT (PA/FO), indicando a percentagem de pontos obtidos sobre o máximo possível em todo o questionário. Os índices ITOT correspondem à média aritmética dos índices parciais TOT I, TOT II, TOT III e TOT IV. Esses índices são úteis para a interpretação dos resultados do questionário, porque dão uma noção geral das necessidades discriminadas por qualidade física.

Finalmente, temos o Índice de Autonomia Exprimida (IAE). Os outros índices (TOTs, ITOTs etc.) representam uma noção parcial ou total das necessidades para cada uma das qualidades físicas observadas, sem reproduzir sua interação. Para tornar possível a comparação dos resultados do questionário com o teste de campo, necessitava-se de um índice representativo do conjunto dos seus items. Ou seja, um valor global, tendo uma relação simultânea com as necessidades hipotéticas associadas à força e potência aeróbia. A estratégia de somar os índices ITOT (PA) e ITOT (FO), ainda que justificável do ponto de vista estatístico (pode-se adicionar valores ordinais), seria logicamente vulnerável: é difícil defender que se possa somar valores relativos a qualidades tão diversas quanto a potência aeróbia e a força.

Decidimos, então, reduzir os totais parciais do questionário a um fator representativo dos resultados de todas as partes, através da análise fatorial (componentes principais). Muitos autores aplicaram esse procedimento em diversos contextos da pesquisa gerontológica ${ }^{13,15,16,44-46}$. Um dos objetivos dessa utilização é a determinação de índices associados a questionários e entrevistas: procura-se definir os fatores que são associados a um certo número de itens de um instrumento. A identificação de 'grupos de itens' torna mais fácil a interpretação das respostas às questões. Este estudo segue um caminho similar, reduzindo por meio da definição de seus componente principais, os oito índices parciais do QSAP (índices TOT) a um índice único, representativo do comportamento do conjunto destes índices. Os índices TOT foram escolhidos porque são independentes entre si: eles representam o total de pontos obtidos por cada qualidade física, em cada parte do questionário, sem que seus valores influenciem-se mutuamente. Posteriormente, uma regressão múltipla entre estas oito variáveis e os escores fatoriais referentes ao fator de maior peso foi calculada. Isso permitiu o desenvolvimento de uma equação para o IAE, englobando todos os índices TOT. As seções seguintes descrevem as etapas da construção do IAE, bem como a verificação de sua representatividade no que toca ao questionário como um todo.

\section{CONSTRUÇÃO DO ÍNDICE DE AUTONOMIA EXPRIMIDA (IAE)}

\section{1) População}

Foram aplicados 164 questionários a indivíduos de 60 a 93 anos ( $\overline{\mathrm{X}}=69,88 \pm 6,99$ anos $)$, habitando a cidade de Bruxelas, Bélgica. Dentre esses, 13 viviam em instituições (asilos) ( $\overline{\mathrm{X}}=80 \pm 7,36$ anos $)$ e 151 viviam em suas casas $(\overline{\mathrm{X}}=$ $69,01 \pm 6,26$ anos). A administração do questionário foi individual. Após uma explicação detalhada dos objetivos e do processo de aplicação do intrumento, a entrevista desenrolava-se segundo a ordem proposta pela matriz do QSAP (Anexo 1). As folhas de resposta eram distribuídas de acordo com sua necessidade. Na medida do possível, apenas as informações fornecidas pelo questionário eram apresentadas ao entrevistado. Contudo, se isso não era suficiente para a compreensão de um item, davam-se explicações mais detalhadas. O tempo de aplicação do QSAP variou entre 11 e 30 minutos ( $\overline{\mathrm{X}}=18,70 \pm 3,47 \mathrm{~min})$, o que é comparável ao tempo de duração de outros instrumentos concebidos para pessoas idosas ${ }^{6,10,18,26,47}$.

\section{2) $O$ Índice IAE}

Os índices TOT foram as variáveis independentes a partir das quais o índice geral do QSAP deveria ser calculado. As razões dessa escolha já foram mencionadas. Antes de começar o processo de redução destas variáveis, verificou-se a normalidade de sua distribuição. Para tal, três critérios foram adotados: a análise dos coeficientes de assimetria e de curtose (entre $-0,5$ e 0,5), o teste $d$ de Kolmogorov-Smirnov ( $p>0,05)$ e a estratégia do normal-plot (escores $z$ x resíduos). A distribuição era aceita como normal se satisfizesse a dois desses três critérios. Os resultados indicaram bons níveis de normalidade para os índices TOT referentes às três primeiras partes do questionário. Para os índices TOT IV (PA) 
e TOT IV (FO), os valores para a curtose foram elevados, mas as distribuições tiveram um perfil simétrico. A ausência de normalidade pareceu dever-se a excessiva concentração de valores no centro da distribuição. Lembramos, contudo, que essa parte do QSAP reflete a opinião do entrevistador sobre as necessidades dos entrevistados. Uma vez que os sujeitos de nossa amostra tinham nível socioeconômico equivalente, é normal que essa opinião não varie muito. Uma composição mais heterogênea da população poderia corrigir o perfil da distribuição, já que o nível de exigências para as atividades físicas da vida cotidiana seria também mais variado. Em nossa opinião, a ausência de normalidade para essa parte do questionário não deveria ser a priori tida como inerente ao instrumento, mas antes como um resultado influenciado pelo fato de a amostra não ter sido perfeitamente randômica. Dessa forma, considerou-se que a distribuição dos índices TOT satisfazia os critérios mínimos para a aplicação da análise fatorial. Todos os cálculos foram realizados por meio do programa Statistica for Windows, versão 1994 (Microsoft Corporation).

A análise fatorial iniciou-se pelo cálculo da matriz de correlações entre os oito índices TOT. Essa matriz foi submetida à extração de componentes principais, seguida de rotação varimax (tabela 1). Dois fatores foram selecionados para interpretação das relações entre os subtotais do questionário (valores eigen $>1,0)$. O primeiro fator (valor eigen $=4,36$ ) concentrou uma proporção significativamente maior da variância das variáveis de entrada, em comparação à variância integrada pelo segundo fator (valor eigen $=1,69$ ). O primeiro fator explicou $54,44 \%$ da variância do conjunto dos índices TOT, em uma solução que respondeu por $75,65 \%$ da variância total. Essa concentração de variância no primeiro fator é superior ao comunicado por outros estudos que objetivaram a definição de escores simples a partir de variáveis múltiplas, ou a determinação de fatores principais associados a aspectos comuns entre as variáveis de entrada ${ }^{12,14,15}$, ${ }^{49-51}$. Assim, considerou-se que as saturações do primeiro com-

\section{TABELA 1}

Saturações (varimax) - Análise de componentes principais

\begin{tabular}{lcc}
\multicolumn{1}{c}{ Variável } & Fator $\mathbf{1}$ & Fator $\mathbf{2}$ \\
TOT I (PA) & 0,715 & 0,426 \\
TOT I (FO) & 0,757 & 0,336 \\
TOT II (PA) & 0,831 & 0,082 \\
TOT II (FO) & 0,834 & 0,156 \\
TOT III (PA) & $-0,117$ & $-0,969$ \\
TOT III (FO) & $-0,131$ & $-0,969$ \\
TOT IV (PA) & 0,817 & 0,002 \\
TOT IV (FO) & 0,821 & 0,059 \\
valor eigen & 4,36 & 1,69 \\
\% variância total & 54,44 & 21,21 \\
\% variância acumulada & 54,44 & 75,65 \\
\hline
\end{tabular}

ponente poderiam ser utilizadas para o cálculo de um índice representativo do comportamento geral do QSAP.

O passo seguinte consistiu no cálculo dos escores fatoriais associados ao componente principal. A cada indivíduo foi atribuído um escore do tipo $\sum \mathrm{a}_{\mathrm{i}} \mathrm{x}_{\mathrm{i}}$, onde $\mathrm{a}_{\mathrm{i}}$ correspondia à saturação do primeiro componente e $\mathrm{x}_{\mathrm{i}}$ a cada um dos índices TOT. Com a finalidade de testar a representatividade desses escores com respeito aos resultados gerais do questionário, determinou-se a correlação entre seus valores e os dos índices ITOT (PA) e ITOT (FO). Conforme as expectativas, o $r$ de Pearson entre os escores fatoriais e esses dois índices foi elevado $(r=0,90, p<0,001)$, indicando que os escores calculados com base no primeiro fator permitem um prognóstico satisfatório do comportamento do questionário como um todo. Precisava-se, porém, encontrar um meio de representar esses escores a partir das variáveis de origem, por meio de uma equação de regressão. Na intenção de verificar se a utilização de técnicas paramétricas de regressão seria um procedimento adequado, testou-se a normalidade da distribuição dos escores fatoriais, como havia sido feito para os índices TOT. A distribuição dos escores fatoriais e dos índices ITOT revelou-se normal, autorizando-nos a aplicar essa estratégia estatística.

Calculou-se uma regressão múltipla, na qual os escores fatoriais foram a variável dependente e os índices ITOT (PA) e ITOT (FO) foram as variáveis independentes. O sumário dos resultados da regressão múltipla entre os escores fatoriais e os índices ITOT (PA) e ITOT (FO) encontra-se na tabela 2. Ele indica que a equação tem excelente grau de ajustamento aos valores da variável dependente. Os coeficientes de regressão B e beta são altamente significativos e os valores de $t$, para um grau de liberdade de 161, confirmam a validade do modelo. Constata-se que o intercepto é significativamente diferente de 0 , e que os coeficientes B e beta são todos diferentes entre si ( $p<0,001)$. A informação fornecida pelos coeficientes B e beta é essencialmente a mesma. Contudo, estes últimos são calculados após uma padronização de todas as variáveis de acordo com uma média de 0 e um desvio-padrão de 1. Assim, a magnitude dos coeficien-

\section{TABELA 2}

Sumário da regressão múltipla entre os escores fatoriais e os índices ITOT ( $n=164$ )

\begin{tabular}{|c|c|c|c|c|c|c|}
\hline \multirow[b]{2}{*}{$n=164$} & \multirow[b]{2}{*}{ Beta } & \multicolumn{5}{|c|}{ 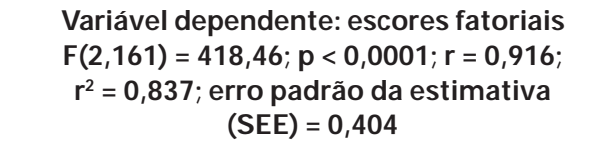 } \\
\hline & & SEE beta & B & SEE B & $t(161)$ & $\mathbf{p}$ \\
\hline Intercepto & & & $-3,423$ & 0,123 & $-27,891$ & 0,000000 \\
\hline ITOT (PA) & 0,456 & 0,089 & 7,496 & 1,459 & 5,137 & 0,000001 \\
\hline ITOT (FO) & 0,474 & 0,089 & 7,899 & 1,482 & 5,137 & 0,000000 \\
\hline
\end{tabular}


tes beta permite a comparação da contribuição relativa de cada variável independente à equação final. Como é evidente em nosso modelo, a contribuição das duas variáveis é equilibrada.

A seguir, os escores brutos calculados pela equação de regressão foram transformados em uma unidade standard, segundo a média e o desvio-padrão de nossa população. Esse procedimento era necessário para que pudéssemos comparar o índice IAE ao índice obtido pelo teste de campo (aptidão física): uma vez que os dois índices são expressos em uma mesma unidade, uma relação entre os dois pode ser mais facilmente determinada. A criação de escores standard é freqüente em estudos que comparam grandezas de natureza diferente. Em geral, parte-se da definição de escores z para toda padronização. Thomas e Nelson ${ }^{52}$ mencionam ainda os escores $T$. Estes escores corrigem os escores z para uma média de 50 e um desvio-padrão de 10 (escore $T=$ score $z$ x 10 +50), o que facilita a interpretação dos dados, pois eliminam-se valores negativos e decimais (por exemplo, um escore $z$ de $-1,00$ equivale a um escore $T$ de 40).

Em nosso caso específico, uma variação do método dos escores $T$ foi utilizada: ela consiste em multiplicar os escores $z$ pelo desvio-padrão, adicionando-se posteriormente este produto à média de idade de uma população. Estes valores são homólogos aos dos escores $z$ e $T$, mas permitem visibilização mais imediata da posição relativa de um indivíduo em relação a outras pessoas de mesma idade cronológica. Assim, se um indivíduo tem 70 anos, e seu IAE é de 85 , suas necessidades em termos de força e de produção de energia para o trabalho são inferiores àquelas de um indivíduo cujo IAE é de 50. Essa estratégia foi utilizada em outros estudos, como no cálculo do Índice de Idade ADL (ADL Age Index) de Kim e Tanaka ${ }^{15}$. Os escores $z$ são calculdos de maneira que sua média seja 0,0 e seu desvio-padrão 1,0 . Ora, os escores fatoriais têm exatamente estas características, sendo equivalentes aos escores z. Como o modelo de regressão exibido na tabela $2\left(\mathrm{IAE}_{\text {brut }}\right)$ tem grau de ajustamento elevado, os valores previstos são praticamente idênticos aos escores $z$. Por razões práticas, consideramo-los como tais. Assim, o índice IAE é calculado de acordo com as seguintes equações:

$$
\mathrm{IAE}=6,99 \times \mathrm{IAE}_{\text {brut }}+69,88,
$$

onde $\mathrm{IAE}_{\text {brut }}=7,496 \mathrm{x}_{1}+7,899 \mathrm{x}_{2}-3,423$, onde $\mathrm{x}_{1}=\mathrm{ITOT}(\mathrm{PA}), \mathrm{x}_{2}=\mathrm{ITOT}(\mathrm{FO})$

\section{3) Representatividade do Índice IAE}

Com o intuito de testar a capacidade de previsão e a estabilidade de nossa equação de regressão, foram aplicadas duas estratégias: a) comparação do índice IAE aos valores dos índices TOT - como os índices ITOT (PA) e ITOT (FO) representam a percentagem total de pontos obtidos nos índices parciais, foi testada a hipótese de que uma correlação positiva deveria existir entre o índice IAE e os oito índices TOT; b) uma validação cruzada para o índice IAE, calculada para um segundo grupo de respondentes ao QSAP. Essa validação considerou a relação do IAE com os índices ITOT e com a idade.

As comparações entre o IAE e os parâmetros de referência foram feitas pelo coeficiente de correlação de Pearson $(r)$ e pelo coeficiente de correlação de Spearman $\left(r_{s}\right)$, de acordo com a natureza das variáveis. A idade é uma variável intervalar, habitualmente tratada com auxílio de técnicas estatísticas paramétricas. A distribuição do IAE é obrigatoriamente normal, pois esse índice guarda relação direta com os escores fatoriais (cuja distribuição foi testada). No que diz respeito aos índices TOT, visto que as distribuições não foram sempre normais, preferiu-se utilizar o coeficiente não-paramétrico de Spearman.

Os coeficientes de correlação encontrados entre o IAE e os índices TOT encontram-se na tabela 3. Eles demonstram que o índice IAE é fortemente associado à maior parte dos índices parciais do QSAP. No entanto, os índices TOT III (PA) e TOT III (FO) exibiram uma relação claramente inferior que os demais, o que poderia sugerir que sua contribuição à cotação geral do instrumento é menos importante que a dos outros índices. Como a população analisada era majoritariamente composta de indivíduos cujo nível de aptidão funcional era elevado, imaginou-se que essa correlação frágil poderia advir de um artefato da amostra. Por isso, a análise foi repetida, apenas para os sujeitos que viviam em instituições. Os novos resultados encontram-se na tabela 4.

Constata-se que o perfil de correlações muda completamente quando observamos uma população cujo volume de atividades cotidianas é baixo, mas que não se conforma com essa situação. Para o grupo de indivíduos institucionalizados, a cotação reduzida nas Partes I e II do QSAP foi sistematicamente acompanhada por uma cotação superior na Parte III. Nestes casos, os índices TOT III (PA) e TOT III (FO) consistem nas fontes principais de pontos para a formação do IAE. Pode-se então afirmar que a importância dos índices parciais, na composição do IAE, depende das características

\section{TABELA 3}

Correlações de Spearman entre o IAE e os

índices TOT - total de sujeitos $(n=164)$

\begin{tabular}{lcrc}
\hline Índices & \multicolumn{1}{c}{$\mathbf{r}_{\mathbf{s}}$} & $\mathbf{t}(\mathbf{n}-\mathbf{2})$ & $\mathbf{p}$ \\
TOT I (PA) & $0,543 * * *$ & 8,22 & 0,000000 \\
TOT I (FO) & $0,606 * * *$ & 9,69 & 0,000000 \\
TOT II (PA) & $0,755^{* * *}$ & 14,68 & 0,000000 \\
TOT II (FO) & $0,741 * * *$ & 14,06 & 0,000000 \\
TOT III (PA) & $0,304 * * *$ & 4,07 & 0,000073 \\
TOT III (FO) & $0,277 * * *$ & 3,66 & 0,000336 \\
TOT IV (PA) & $0,624 * * *$ & 10,18 & 0,000000 \\
TOT IV (FO) & $0,616 * * *$ & 9,97 & 0,000000 \\
\hline
\end{tabular}

*** $\mathrm{p}<0,001$; ns: não-significativo 
da população estudada, mas que todos têm peso universal equivalente. Em conclusão, a equação de regressão investese de boa representatividade, no que toca aos índices de cada parte do QSAP, exprimindo razoavelmente bem o comportamento dos itens que contribuem para a formação dos índices ITOT.

A validação cruzada teve por objetivo a verificação da estabilidade da equação do IAE, pela determinação da correlação e do erro padrão (SEE) entre os valores reais e os valores previstos (no presente estudo, entre o IAE e os escores factoriais). $\mathrm{O}$ erro padrão é determinado pela fórmula $\mathrm{SEE}=$ $\left[\sum\left(\mathrm{X}-\mathrm{X}^{\prime}\right)^{2} / \mathrm{N}\right]^{1 / 2}$, onde $\mathrm{X}$ corresponde ao escore observado (escore fatorial), $\mathrm{X}^{\prime}$ ao escore previsto (IAE) e $\mathrm{N}$ ao número de sujeitos da amostra. O questionário foi reaplicado a uma amostra de 20 indivíduos ( $\overline{\mathrm{X}}=67,40 \pm 5,39$ anos). Os procedimentos de aplicação foram rigorosamente os mesmos que para a população original.

As correlações entre o índice IAE e os índices TOT (PA) e TOT (FO) são exibidas na tabela 5. As correlações obtidas para os índices TOT foram similares àquelas obtidas na população original, apesar dos coeficientes não-significativos para os índices TOT III (FO) e TOT IV (FO). Os escores fatoriais para a nova amostra foram calculados (através da análise fatorial), para que se pudesse compará-los com os resultados do IAE. Os SEE, entre os novos escores fatoriais e os valores previstos pela equação de regressão, aproximaram-se relativamente dos valores obtidos para a população original. Na amostra de 164 indivíduos, o erro havia sido de 0,404 , enquanto na nova amostra o IAE aparece associado a um SEE de 0,368. Deve-se, contudo, lembrar que a estabilidade da equação deve ser testada para amostras maiores. Por exemplo, para que se distinga entre desvios-padrão de $2,5 \%$ e 3,5\%, uma amostra de $n=20$ parece suficiente, mas para uma discriminação de desvios de $2,5 \%$ a 3,0\%, o número de sujeitos deveria ser de ao menos $80^{53}$. Assim, o refinamento futuro do modelo proposto dependerá de sua aplicação em maior escala.

\begin{tabular}{|c|c|c|c|}
\hline \multicolumn{4}{|c|}{$\begin{array}{c}\text { TABELA } 4 \\
\text { Correlações de Spearman entre o IAE e os índices } \\
\text { TOT - sujeitos institucionalizados }(n=13)\end{array}$} \\
\hline Índices & $\mathbf{r}_{\mathrm{s}}$ & $t(n-2)$ & $\mathbf{p}$ \\
\hline TOT I (PA) & $-0,258 \mathrm{~ns}$ & $-0,88$ & 0,394 \\
\hline TOT I (FO) & $0,110 \mathrm{~ns}$ & 0,37 & 0,720 \\
\hline TOT II (PA) & 0,305 ns & 1,06 & 0,311 \\
\hline TOT II (FO) & $0,348 \mathrm{~ns}$ & 1,23 & 0,245 \\
\hline TOT III (PA) & $0,678^{*}$ & 3,06 & 0,011 \\
\hline TOT III (FO) & $0,719 * *$ & 3,43 & 0,005 \\
\hline TOT IV (PA) & $0,263 \mathrm{~ns}$ & 0,90 & 0,386 \\
\hline TOT IV (FO) & $0,423 \mathrm{~ns}$ & 1,55 & 0,149 \\
\hline
\end{tabular}

Os resultados concernentes à relação entre os índices ITOT e os escores fatoriais foram semelhantes aos da população original, sendo de $r=0,91$ para o ITOT (PA) e de $r=0,92$ para o ITOT (FO), para um nível de significância de $95 \%$. Da mesma forma, a relação do IAE com a idade cronológica foi significativo em ambas as amostras $(\mathrm{p}<0,05)$, ainda mais importante para a validação cruzada $(\mathrm{r}=-0,43)$ que para a amostra original $(r=-0,18)$. Além disso, a correlação entre a idade e o IAE é do tipo inverso, o que é natural: quanto mais avançados em idade, menos atividades os indivíduos fazem em seu cotidiano. Não obstante, nota-se que essas correlações são baixas. Quer dizer que, apesar da existência de certa relação entre as variáveis, elas representam noções bem diversas: as necessidades para uma vida fisicamente autônoma, considerando-se igualmente o volume habitual de atividades, o contexto físico (meio ambiente físico) e os desejos pessoais, não são necessariamente determinadas pela idade ou mesmo pela aptidão física dos indivíduos. Pode-se considerar esses resultados como uma evidência da boa validade conteúdo do QSAP.

\section{4) Considerações finais e conclusão}

Este estudo objetivou a determinação de um índice representativo dos pontos obtidos em cada parte de um questionário sobre as necessidades para a autonomia de ação de indivíduos de mais de 60 anos, o Questionário Senior de Atividades Físicas (QSAP). Este índice deveria guardar uma relação com as necessidades em termos de força de membros superiores e de capacidade de produção de energia para o trabalho, respeitando as características psicométricas destas variáveis.

O método utilizado para reduzir os índices parciais do QSAP (índices TOT) a um escore simples é consistente com outros estudos no campo da medida e da avaliação em gerontologia. Por exemplo, certos trabalhos utilizaram a análise de compontentes principais para definir escores representativos da capacidade física, da idade biológica ou da idade

\begin{tabular}{lccc}
\hline & $\begin{array}{c}\text { TABELA 5 } \\
\text { Correlações de Spearman entre o IAE e os } \\
\text { índices TOT - validação cruzada (n = 20) }\end{array}$ \\
\hline Índices & \multicolumn{1}{c}{$\mathbf{r}_{\mathbf{s}}$} & $\mathbf{t}(\mathbf{n}-\mathbf{2})$ & $\mathbf{p}$ \\
TOT I (PA) & $0,519 *$ & 2,58 & 0,018 \\
TOT I (FO) & $0,478^{*}$ & 2,31 & 0,032 \\
TOT II (PA) & $0,539^{*}$ & 2,71 & 0,014 \\
TOT II (FO) & $0,589^{*} *$ & 3,10 & 0,006 \\
TOT III (PA) & $0,490^{*}$ & 2,38 & 0,028 \\
TOT III (FO) & 0,360 ns & 1,64 & 0,118 \\
TOT IV (PA) & $0,376 *$ & 1,72 & 0,042 \\
TOT IV (FO) & 0,038 ns & 0,08 & 0,884 \\
\hline$* p<0,05 ; * * p<0,01 ;$ ns: não-significativo & &
\end{tabular}

Rev Bras Med Esporte - Vol. 4, № 2 - Mar/Abr, 1998 
funcional, a partir de uma série de variáveis biológicas ou de desempenho ${ }^{11,14,15}$. Outros dedicaram-se à redução de itens de questionários de avaliação da saúde ou das atividades físicas realizadas no dia-a-dia ${ }^{50,51,54-58}$. A ênfase principal desses estudos foi a identificação dos fatores gerais em torno dos quais certo número de variáveis poderia ser agrupado. Este estudo utilizou a mesma estratégia mas, posteriormente, o fator principal foi utilizado para definir uma variável independente que serviria de base à formação de um índice mais fácil de calcular e interpretar.

Deve-se notar que o componente principal identificado respondia por cerca de $54 \%$ da variância total dos índices parciais do QSAP. Essa concentração é maior do que a da maior parte dos estudos que utilizaram a mesma estratégia de redução ${ }^{11,12,15,49,59}$. Mais ainda, o valor eigen do primeiro fator foi duas vezes maior do que o do segundo. É, então, razoável pensar que esse componente possa ser adotado como ponto de partida da definição de um índice geral para o questionário.

Em conclusão, nossos resultados indicam que os níveis de estabilidade e de capacidade de previsão do IAE são aceitáveis, e que ele pode ser utilizado como um índice confiável do perfil global de informações do QSAP. Porém, é importante observar que a representatividade do IAE foi estabelecida com base em dados transversais, provenientes de uma população excessivamente homogênea. Assim, são necessários estudos que analisem o comportamento desse índice com base em observações longitudinais, e que estimem sua estabilidade e representatividade junto a populações cujos contextos físico, econômico e sociocultural sejam diferentes. Finalmente, outros critérios de validação devem ser aplicados. A generalização do modelo de regressão depende da confirmação de sua pertinência (validade de estrutura, consistência interna, validade concorrente e concomitante) e de sua reprodutibilidade. Essas etapas são fundamentais para que o QSAP venha a ser uma ferramenta útil no estudo da autonomia da pessoa idosa, isoladamente ou combinado ao segundo instrumento do sistema de avaliação do qual faz parte, o Teste Senior de Caminhar e Transportar.

\section{AGRADECIMENTOS}

Paulo Farinatti é bolsista do CNPq, modalidade doutorado no Exterior, processo no 200063/94-4.

\section{REFERÊNCIAS}

1. McDowell I, Newell C. Measuring health: a guide to rating scales and questionnaires. New York: Oxford University Press, 1987.

2. Applegate WB, Blass JP, Williams TF. Instruments for the functional assessment of older patients. N Eng J Med 1990;322:1207-14.

3. Colvez A, Gardent H, Bucquet D. Validation d'indicateurs en gérontologie: application au domaine des indicateurs de capacité fonctionnelle. In: Colvez A, Gardent H, editors. Les indicateurs d'incapacité fonctionnelle en gérontologie. Paris: CTNERHI-INSERM, 1990:37-77.
4. Guyatt GNH, Eagle DJ, Sackett B, Willan A, Griffith L, McIlroy W, et al. Measuring quality of life in the frail elderly. J Clin Epidemiol 1993;46: 1433-44.

5. Hubert HB, Bloch DA, Fries JF. Risk factors for physical disability in an aging cohort: the NHANES I Epidemiologic Follow-up Study. J Rheumatol 1993;20:480-8.

6. Washburn RA, Smith KW, Jette AM, Janney CA. The Physical Activity Scale for the Elderly (PASE): development and evaluation. J Clin Epidemiol 1993;46:153-62.

7. Whittle H, Goldenberg D. Functional health status and instrumental activities of daily living performance in noninstitutionalized elderly people. J Adv Nurs 1996;23:220-7.

8. Farinatti, PTV. Avaliação da autonomia do idoso: definição de critérios para uma abordagem positiva a partir de um modelo de interação saúde-autonomia. Arq Geriatr Gerontol 1997;1:31-8

9. Keith RA, Granger CV, Hamilton BB, Sherwin FS. The Funtional Independence Measure: a new tool for rehabilitation. In: Eisenberg MG, Grzesiak RC, editors. Advances in Clinical Rehabilitation. New York: Springer, 1987:6-18.

10. Gloth III FM, Walston J, Meyer J, Pearson J. Reliability and validity of the Frail Elderly Functional Assessment Questionnaire. Am J Phys Med Rehabil 1995;74:45-53.

11. Chodzko-Zadjko, WJ, Ringel RC. Physical fitness measures and sensory and motor performance in aging. Exp Gerontol 1987;22:317-28.

12. Nakamura E, Miyao K, Ozeki T. Assessment of biological age by principal component analysis. Mech Ageing Dev 1988;46:1-18

13. Facchini F, Gueresi P, Pettener D. Biological age in Italian adults: influence of social and behavioural factors. Ann Hum Biol 1992;19:403-20.

14. Daltroy LH, Phillips CB, Eaton HM, Larson MG, Partridge AJ, Logigian $\mathrm{M}$, et al. Objectively measuring physical ability in elderly persons: the physical capacity evaluation. Am J Public Health 1995;85:558-60.

15. Kim SH, Tanaka K. The assessment of functional age using 'activities of daily living' performance tests: astudy of Korean women. J Aging Phys Activity 1995;3:39-53.

16. Lee MS, Tanaka K, Nakagaichi M, Nakadomo F, Watanabe K, Takeshima N, et al. The relative utility of health-related fitness tests and skilled motor performance tests as measures of biological age in Japanese men. Appl Human Sci 1996;15:97-104

17. Montoye HJ, Kemper HCG, Saris WHM, Washburn RA. Measuring Physical Activity and Energy Expenditure. Champaign: Human Kinetics, 1996.

18. Dipietro L, Caspersen CL, Ostfeld AM, Nadel ER. A survey for assessing physical activity among elder adults. Med Sci Sports Exerc 1993; $25: 628-42$

19. Weiss TW, Slater CH, Green LW, Kennedy VC, Albrigth DL, Wun C-C. The validity of single-item, self-assessment questions as measures of adults physical activity. J Clin Epidemiol 1990;43:1123-9.

20. Wolf AM, Hunter DJ, Colditz GA, Manson JE, Stampfer MJ, Corsano KA, et al. Reproducibility and validity of a self-administered physical activity questionnaire. Int J Epidemiol 1994;23:991-9.

21. Sauvel C, Barberger-Gateau P, Dequae L, Letenneur L, Dartigues JF. Facteurs associés à l'évolution à un an de l'autonomie fonctionnelle des personnes âgées vivant à leur domicile. Rev Epidémiol Santé Publique 1994;42:13-23.

22. Ainsworth BE, Haskell WL, Leon AS, Jacobs DR, Montoye HJ, Sallis JF, et al. Compendium of physical activities: classification of energy costs of human physical activities. Med Sci Sports Exerc 1993a;25:71-80.

23. Paffenbarger RS, Wing AL, Hyde RT, Jung DL. Physical activity and incidence of hypertension in college alumni. Am J Epidemiol 1983;117: 245-57. 
24. Paffenbarger RS, Blair SN, Lee IM, Hyde RT. Measurement of physical activity to assess health effects in free-living populations. Med Sci Sports Exerc 1993;25:60-70.

25. Caspersen CJ, Bloemberg BPM, Saris WHM, Merrit RK, Kromhout D. The prevalence of selected physical activities and their relation with coronary heart disease risk factors in elderly men: the Zutphen study, 1985. Am J Epidemiol 1991;133:1078-92.

26. Voorrips LE, Ravelli AC, Dongelmans PCA, Durenberg P, Van Staveren WA. A physical activity questionnaire for the elderly. Med Sci Sports Exerc 1991;23:974-9.

27. Ainsworth BE, Leon AS, Richardson MT, Jacobs DR, Paffenbarger RS Accuracy of the College Alumnus Physical Activity Questionnaire. J Clin Epidemiol 1993b;46:1403-11.

28. Richardson MT, Leon AS, Jacobs DR, Ainsworth BE, Serfass R. Comprehensive evaluation of the Minnesota Leisure Time Physical Activity Questionnaire. J Clin Epidemiol 1994;47:271-81.

29. van Bennekom CAM, Jelles F, Lankhorst GJ, Bouter LM. The rehabilitation activities profile: a validation study of its use as a disability index with stroke patients. Arch Phys Med Rehab 1995;76:501-7.

30. Rosenbloom S. Transportation needs of the elderly population. Clin Geriatr Med 1993;9:297-310.

31. Thompson I. Woldenberg Village: an illustration of supportive design for older adults. Exp Aging Res 1994;20:239-44.

32. Roper TA, Mulley GP. Caring for older people: public transport. BMJ 1996;313:415-8

33. Cress ME, Schechtman KB, Mulrow CD, Fiatarone MA, Gerety MB, Buchner DM. Relationship between physical performance and self-perceived physical function. J Am Geriatr Soc 1995;43:93-101.

34. Posner JD, McCully KK, Landsberg LA, Sands LP, Tycenski P, Hofmann MT, et al. Physical determinants of independence in mature women. Arch Phys Med Rehab 1995;76:373-80.

35. Young DR, Sharp DS, Curb D. Associations among baseline physical activity and subsequent cardiovascular risk factors. Med Sci Sports Exerc 1995;27:1646-54.

36. Wiktorin C, Hjelm EW, Winkel J, Köster M. Reproducibility of a questionnaire for assessment of physical load during work and leisure time. J Occup Environ Med 1996;38:190-201.

37. Wiktorin C, Karlqvist L, Winkel J. Stockolm MUSIC I Study Group: validity of self-reported exposures to work postures and manual materials handling. Scand J Work Environ Health 1993;18:208-14.

38. Taylor HL, Jacobs DR, Schucker B, Knudsen J, Leon AS, De Backer G. A questionnaire for the assessment of leisure time physical activities. J Chronic Dis 1978;31:741-55.

39. Gionet NJ, Godin G. Self-reported exercise behavior of employees: a validity study. J Occup Med 1989;31:969-73.

40. Hopkins WG, Wilson NC, Russell DG. Validation of the Physical Activity Instrument for the Life in New Zealand National Survey. Am J Epidemiol 1991;133:73-82.

41. Elosua R, Marrugat J, Molina L, Pons S, Pujol E. Validation of the Minnesota Leisure Time Physical Activity Questionnaire in Spanish men. Am J Epidemiol 1994;139:1197-209.
42. Pheasant S. Ergonomics, work and helth. London: MacMillan Press, 1991.

43. Winkel J, Westgaard R. Occupational and individual risk factors for shoulder-neck complaints. Part II. The scientific basis (litterature review) for the guide. Int J Ind Ergonomics 1992;10:85-104.

44. Cialdella P, Guillaud Bataille JM, Gausset MF, Terra JL, Gerin P, Palliard E, et al. Etude sur l'unidimensionnalite de l'echelle de depression geriatrique de Yesavage et Brink. Comparaison entre methodes classiques et modele de Rasch. Encephale 1992;18:537-44.

45. Jobert M, Escola H, Poiseau E, Gaillard P. Automatic analysis of sleep using two parameters based on principal component analysis of electroencephalography spectral data. Biol Cybern 1994;71:197-207.

46. Freyer G, Maire P, Ardiet C, Tranchand B, Droz JP. Chimiotherapies cytotoxiques et sujets âgés: constats et perspectives. Bull Cancer Paris 1995;82:531-40

47. Katz MM, Lyerly SB. Methods for measuring adjustement and social behavior in the community. I - rationale, description, discriminative validity and scale developement. Psychol Rep 1963;13:503-35.

48. Mahoney FI, Barthel DW. Functional evaluation: the Barthel Index. Md Med J 1965;14:61-5.

49. Hofecker G, Skalicky M, Kment A, Niedermuller H. Models of biological age of the rats: I. a factor model of age parameters. Mech Ageing Dev 1980;14:345-59.

50. Yoshida K, Matsuoka H, Omae T, Fujii J. Patient-hospital relationship and quality of life in elderly patients with hypertension. Hypertens Res 1995; 18:77-83.

51. Hill KD, Scwarz JA, Kalogeropoulos AJ, Gibson SJ. Fear of falling revisited. Arch Phys Med Rehabil 1996;77:1025-9.

52. Thomas JR, Nelson JK. Research Methods in Physical Activity. 2 ed. Champaign: Human Kinetics, 1990.

53. Laukkanen R. Developement and evaluation of a 2-km walking test for assessing maximal aerobic power of adults in field conditions. Tampere: President Urho Kaleva Kekkonen Institute for Health Promotion, 1993.

54. Alexy BB. Factors associated with participation or nonparticipation in a workplace wellness center. Res Nurs Health 1991;14:33-40.

55. Dunn LA, Rout U, Carson J, Ritter SA. Occupational stress amongst care staff working in nursing homes: an empirical investigation. J Clin Nurs 1994;3:177-83.

56. Ohta Y, Kawasaki N, Araki K, Mine M, Honda S. The factor structure of the general health questionnaire (GHQ-30) in Japanese middle-aged and elderly residents. Int J Soc Psychiatry 1995;41:268-75.

57. Pols MA, Peeters PH, Kemper HCG, Collette HJA. Repeatability and relative validity of 2 physical-activity questionnaire in elderly women. Med Sci Sports Exerc 1996;28:1020-5.

58. Quinn ME, Martin P, Johnson MA. Differences in factors of health orientation of older women. Nursingconnections 1996;9:63-70.

59. Tanaka K, Matsuura Y, Nakadomo F, Nakamura E. Assessment of vital age of Japanese women by principal component analysis. Jpn J Phys Educ 1990;35:121-31. 
ANEXO 1

Questonário Senior de Atividades Físicas

(Folha do entrevistador)

\section{Recomendações gerais:}

1) Entreviste uma pessoa por vez, em um ambiente tranqüilo. Evite aglomerações de pessoas em torno do entrevistado, sobretudo se estas serão entrevistadas a seguir.

2) Entregue ao entrevistado unicamente as folhas de resposta. As informações que elas contêm são suficientes ao desenvolvimento da entrevista. Obedeça às instruções impressas em caracter itálico no corpo do questionário.

3) Seja paciente. O entrevistado pode levar certo tempo para responder às questões. Explique cuidadosamente cada item. Distribua as folhas de resposta à medida em que se fazem necessárias, jamais todas de uma vez. Ajude o entrevistado com as opções de resposta, caso ele não seja capaz de ler.

4) Limite-se a recolher as informações. Leia as questões exatamente como se apresentam. Evite calcular a cotação ao mesmo tempo em que realiza a entrevista. Isso pode conduzir a erros.

5) Antes de passar a uma nova seção do questionário, certifique-se de que os itens prévios foram todos convenientemente preenchidos. Evite retomar uma seção, uma vez terminada.

6) Os códigos PA/FO não mencionados no corpo do questionário são determinados segundo normas de classificação em anexo.

\section{Dados individuais}

Nome: Código:

Data Nasc.: Vive Só/Acomp.: Sexo:

Altura (cm): Peso $(\mathrm{kg})$ :

Data da entrevista:

Hora do início da entrevista: HR: MIN

\section{Parte I - O que o entrevistado faz:}

A) DOMICÍLIO

1) A presentamos uma lista de atividades realizadas no domicílio (tarefas caseiras). Com base nesta lista, gostaríamos de saber: a) quais atividades fazem parte do seu cotidiano; b) qual a sua freqüência (no vezes por semana); c) qual a sua duração (tempo de execução, em minutos, sem interrupção prolongada). Importante: se certas atividades fazem parte de seu cotidiano somente durante algumas fases do ano, leve em conta a freqüência e a duração nestes períodos (Entregue ao entrevistado a folha de respostas $A$ ).

\begin{tabular}{|c|c|c|c|c|c|c|c|}
\hline \multicolumn{2}{|c|}{ ATIVIDADE } & \multirow[t]{15}{*}{ Freq } & \multirow[t]{2}{*}{ Dur } & \multirow{2}{*}{$\begin{array}{c}\mathrm{PA} \\
1\end{array}$} & \multirow{2}{*}{$\begin{array}{c}\text { FO } \\
2\end{array}$} & \multirow[t]{2}{*}{ Pts PA } & Pts FO \\
\hline a) & Faxina leve (varrer, aspirar, tirar a poeira, passar a ferro etc.) & & & & & & \\
\hline b) & Faxina pesada (muros e janelas, mudar móveis de lugar etc.) & & & 3 & 2 & & \\
\hline c) & Lavar a louça & & & 1 & 1 & & \\
\hline d) & Cozinhar & & & 1 & 1 & & \\
\hline e) & Transportar cargas pesadas (sem subir escadas) & & & 2 & 3 & & \\
\hline f) & Transportar cargas pesadas (subindo escadas) & & & 3 & 3 & & \\
\hline g) & Fazer compras (supermercado, shopping etc.) & & & 1 & 2 & & \\
\hline h) & Trabalhar no jardim ou no quintal & & & 2 & 2 & & \\
\hline i) & Lava a roupa (manualmente) & & & 1 & 1 & & \\
\hline j) & Fazer reparações leves (trocar lâmpadas, consertar torneiras etc.) & & & 1 & 2 & & \\
\hline k) & Fazer reparações pesadas (pintar paredes, carpintaria, serralheria etc.) & & & 3 & 3 & & \\
\hline I) & Brincar e/ou ocupar-se de crianças & & & 2 & 2 & & \\
\hline m) & Ocupar-se de pessoa idosa ou doente (lavar, vestir etc.) & & & 1 & 2 & & \\
\hline n) & Outra: & & & & & & \\
\hline
\end{tabular}

Cotação das opções: a) $=1 ; b)=2 ; c)=3 ; d)=4 ; e)=0$

Pontos PA $=$ Freq $\times$ Dur $\times$ PA

$\mathrm{DOM}(\mathrm{PA})=$ Soma dos pontos das 6 atividades mais cotadas

$\mathrm{DOM}(\mathrm{PA}) \Rightarrow$

Pontos FO =Freq $\times$ Dur $\times$ FO

$\mathrm{DOM}(\mathrm{FO})=$ Soma dos pontos das 6 atividades mais cotadas $\quad$ DOM $(\mathrm{FO}) \Rightarrow$ 


\section{B) ATIVIDADES PROFISSIONAIS}

2) Apresentamos uma lista de atividades profissionais e suas categorias de intensidade. Gostaríamos de saber a qual categoria pertence sua ocupação profissional principal, bem como: a) a freqüência (no vezes por semana) com que pratica essa atividade; b) o número de horas diárias consagradas a ela. Apenas uma categoria de intensidade pode ser escolhida. (Entregar ao entrevistado a folha de respostas B).

APOSENTADO (Sem ocupação profissional complementar. Indicar o ano da aposentadoria):

\section{TRABALHO SEDENTÁRIO FREQ:__ HORAS:__ IT: 1}

Todas as atividades cuja intensidade de esforço é mínima, durante as quais se fica sentado a maior parte do tempo, ou cujas exigências de deslocamento limitam-se à área do escritório, laboratório etc.
Administrativo (empregados de escritório)

Condutor (carro, ônibus, trem etc.)

Escritor

Prof. liberais (médicos, advogados, professores etc.)

Secretário

Alfaiate, costureiro etc.

\section{TRABALHO LEVE}

Todas as atividades que requerem nível de esforço razoável, mas cuja importância não resida nem em transporte manual de pesos, nem na aplicação contínua e intensa de força muscular. O indivíduo não sente aceleração marcada da respiração ou da freqüência cardíaca, nem transpiração abundante.

HORAS:

IT: 2

\begin{tabular}{|l|}
\hline Padeiro \\
Carpinteiro \\
Guarda de trânsito (urbano) \\
Sapateiro \\
Cozinheiro \\
Enfermeiro \\
Mecânico \\
\hline
\end{tabular}

Serralheiro

Faxineiro

Operador de máquinas pesadas

(industriais ou domésticas)

Encanador

Servente

Camareiro

Vigilantes (guarda-noturno etc.)

\section{TRABALHO PESADO}

FREQ:

HORAS:

IT: 3
Todas as atividades para as quais boa condição física é essencial e que requerem pausas freqüentes de repouso. Atividades que induzem respiração e batimentos cardíacos acelerados, e que provocam transpiração abundante. Atividades que exigem longos deslocamentos a pé, corridas ou aplicação contínua de grande força muscular. Enfim, as atividades baseadas no vigor e na resistência físicas.
Agricultor (trabalhador da terra)

Gari

Lenhador

Estivador

Carteiro

Pedreiro

Mineiro

Pescador

Bombeiro, policial (investigação e prisão)

Carregador (mudanças, demolição etc.)

Cotação das opções: a) $=1 ;$ b) $=2 ;$ c) $=3 ;$ d) $=4$

PROF $(P A)=$ Freq $\times$ Dur $\times I T=$

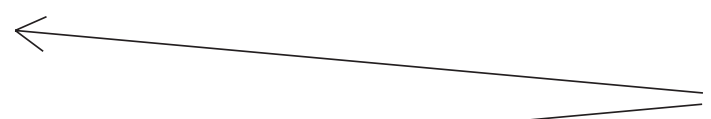

OBS: APOSENTADO $=0$ PONTOS

PROF $(F O)=$ Freq $\times$ Dur $\times I T=$ 


\section{C) ATIVIDADES DE TEMPO LIVRE}

Nesta parte do questionário, é importante fazer a diferença entre as atividades de tempo livre e aquelas que se devem executar (sejam professionais, sejam domésticas). O entrevistador deve dirigir a atenção do entrevistado para as atividades que realiza fora do trabalho ou das obrigações domésticas. Procura-se descobrir: a) quais as atividades mais praticadas; $b$ ) sua freqüência ( $n$ - vezes por semana); c) sua duração (período de execução de cada atividade, em cada sessão).

3) Apresentamos uma lista de atividades. Leia-a com atenção, e em seguida mencione aquelas que pratica em seu tempo livre. Você pode listar até 5 atividades (qualquer número entre 0 e 5). Queira informar-nos igualmente sobre o número de vezes por semana que as pratica, e a duração média de execução. Importante: sinta-se livre para citar atividades que não aparecem na lista. Se a prática de certas atividades é limitada a alguns poucos períodos do ano, leve em conta a freqüência e a duração nestes períodos. Mencione prioritariamente atividades cuja intensidade (nível de esforço físico) seja a maior possível. (Entregue ao entrevistado a folha de respostas C).

\section{ATIVIDADE}

\section{Freq Dur PA FO Pts PA Pts FO}

1)

Cotação das opções: a) $=1 ;$ b) $=2 ; c)=3 ;$ d) $=4$

Pontos PA $=$ Freq $\times$ Dur $\times$ PA

$\operatorname{LIB}(P A)=$ Soma dos pontos das 2 atividades mais cotadas

$\operatorname{LIB}(\mathrm{PA}) \Rightarrow$

Points FO $=$ Freq $x$ Dur $\times$ FO

LIB $(F O)=$ Soma dos pontos das 2 atividades mais cotadas

$\mathrm{LIB}(\mathrm{FO}) \Rightarrow$

\begin{tabular}{|lc|}
\hline Alongamento & $1-1$ \\
Alpinismo/Trekking & $3-3$ \\
Badminton & $2-2$ \\
Basquetebol & $3-2$ \\
Bilhar & $0-1$ \\
Boliche & $1-2$ \\
Caça & $1-2$ \\
Caminhada (passeio) & $1-0$ \\
Caminhada (marcha acelerada) & $2-0$ \\
Ciclismo (passeio) & $2-1$ \\
Ciclismo (velocidade, competição) & $3-2$ \\
Ciclismo (mountain-bike) & $3-3$ \\
Dança & $2-1$ \\
Escultura & $1-2$ \\
Esqui (fundo) & $3-2$ \\
Esqui (montanha) & $2-3$ \\
Escutar música & $0-0$ \\
Futebol (salão e campo) & $3-1$ \\
Golfe & $1-2$ \\
Ginástica (calistenia, tradicional) & $2-1$ \\
Ginástica aérobia (high-impact) & $3-1$ \\
Ginástica aérobia (low-impact) & $2-1$ \\
Handebol & $3-2$ \\
\hline
\end{tabular}

$\begin{array}{lc}\text { Hidroginástica } & 2-1 \\ \text { loga } & 1-1 \\ \text { J ardinagem } & 2-2 \\ \text { J ogging (corrida a pé) } & 3-0 \\ \text { J ogar cartas } & 0-0 \\ \text { Ler } & 0-0 \\ \text { Lutas (judô, jiu-jitsu, caratê, capoeira etc.) } & 2-3 \\ \text { Musculação } & 1-3 \\ \text { Natação } & 3-1 \\ \text { Pintura (quadros) } & 0-1 \\ \text { Pintura (paredes) } & 1-2 \\ \text { Patinagem } & 2-0 \\ \text { Pesca } & 1-2 \\ \text { Petanca/bocha } & 1-1 \\ \text { Remo } & 3-3 \\ \text { Squash } & 3-2 \\ \text { Tocar instrumentos musicais } & 0-1 \\ \text { Tênis } & 3-2 \\ \text { Tiro (arco, armas de fogo etc.)1-1 } & \\ \text { Trabalhos manuais (mecânica, serralheria etc.) } & 1-3 \\ \text { Volibol, netvôlei (sala) } & 2-2 \\ \text { Volibol (praia) } & 3-2 \\ \text { Xadrez/jogo de damas } & 0-0\end{array}$

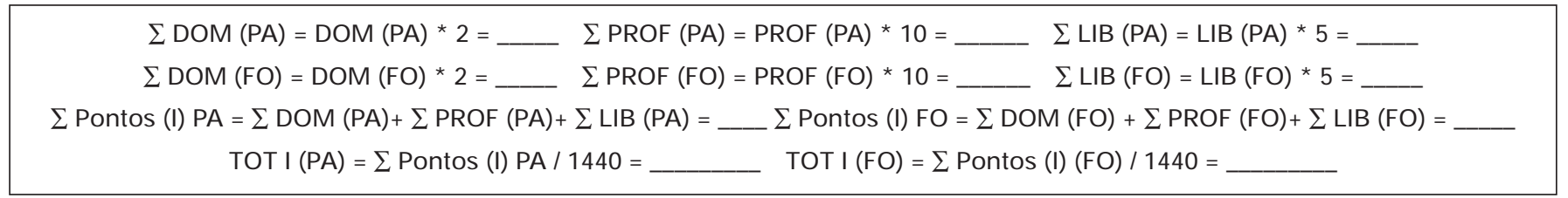




\section{Parte II - O que o entrevistado deve fazer}

4) Quantos lances de escada você é obrigado a subir por dia? (1 lance de escada =10 degraus). (Entregue ao entrevistado a folha de respostas $D$ ).

\begin{tabular}{cccccccccc}
\hline nenhum & 1 a 5 & 6 a 10 & 10 a 15 & $>15$ & & PA & FO & Pontos PA & Pontos PO \\
0 & 1 & 2 & 3 & 4 & $\times$ & 2 & 1 & \\
\hline
\end{tabular}

\section{Multiplique o valor da opção escolhida pelo código PA ou FO}

5) Quantos minutos você deve caminhar até o ponto de transporte coletivo mais próximo de sua casa? Se você só se desloca de carro, marque a opção a) (Entregue ao entrevistado a folha de respostas E)

\begin{tabular}{cccccccccc}
\hline$<5$ & 5 a 10 & 10 a 15 & 15 a 20 & $>20$ & & PA & FO & Pontos PA & Pontos PO \\
0 & 1 & 2 & 3 & 4 & $\times$ & 2 & 1 & \\
\hline
\end{tabular}

Multiplique o valor da opção escolhida pelo código PA ou FO

6) Quantos minutos você deve caminhar até o centro de aprovisionamento (mercado, empório etc) mais próximo de sua casa? Se você só se desloca de carro, marque a opção a) (Entregue ao entrevistado a folha de respostas E)

\begin{tabular}{cccccccccc}
\hline$<5$ & 5 a 10 & 10 a 15 & 15 a 20 & $>20$ & & PA & FO & Pontos PA & Pontos PO \\
0 & 1 & 2 & 3 & 4 & $\times$ & 2 & 1 & \\
\hline
\end{tabular}

Multiplique o valor da opção escolhida pelo código PA ou FO

7) Como você classificaria as condições de seu domicílio, no que diz respeito às dificuldades que você sente atualmente para realizar suas atividades habituais? (Entregue ao entrevistado a folha de respostas F). Grau:

\begin{tabular}{cccccccccc}
\hline muito bom & bom & razoável & ruim & muito ruim & & PA & FO & Pontos PA & Pontos PO \\
0 & 1 & 2 & 3 & 4 & $x$ & 2 & 2 & \\
\hline
\end{tabular}

Multiplique o valor da opção escolhida pelo código PA ou FO

8) De forma geral (não necessariamente em relação a você mesmo), qual a sua opinião sobre as redes de transportes coletivos de sua cidade, no que toca ao grau de adaptação às condições das pessoas de mais de 60 anos? (Entregue ao entrevistado a folha de respostas F). Grau:

\begin{tabular}{cccccccccc}
\hline muito bom & bom & razoável & ruim & muito ruim & & PA & FO & Pontos PA & Pontos PO \\
0 & 1 & 2 & 3 & 4 & $x$ & 2 & 2 & \\
\hline
\end{tabular}

Multiplique o valor da opção escolhida pelo código PA ou FO

9) De forma geral (não necessariamente em relação a você mesmo), como você classificaria seu bairro (ou vizinhança), quanto às dificuldades existentes para a locomoção e a independência das pessoas de mais de 60 anos? (Entregue ao entrevistado a folha de respostas F). Grau:

\begin{tabular}{cccccccccc}
\hline muito bom & bom & razoável & ruim & muito ruim & & PA & FO & Pontos PA & Pontos PO \\
0 & 1 & 2 & 3 & 4 & $x$ & 2 & 2 & \\
\hline
\end{tabular}

\section{Multiplique o valor da opção escolhida pelo código PA ou FO}

10) De forma geral, como você classificaria o grau de trabalho físico exigido para a realização de suas obrigações (atividades que você deve fazer) cotidianas? (Entregue ao entrevistado a folha de respostas $G$ ).

\begin{tabular}{cccccccccc}
\hline muito leve & leve & médio & pesado & muito pesado & & PA & FO & Pontos PA & Pontos PO \\
0 & 1 & 2 & 3 & 4 & $x$ & 2 & 2 & \\
\hline
\end{tabular}


11) Em suas ocupações cotidianas, qual a freqüência associada ao transporte e/ou elevação manual das seguintes cargas: (Entregue ao entrevistado a folha de respostas $H$ ).

\begin{tabular}{|c|c|c|c|c|c|c|c|c|c|c|}
\hline & $a(0)$ & b (1) & $c(2)$ & $d(3)$ & e (4) & & PA & $\mathrm{FO}$ & Pontos PA & Pontos FO \\
\hline $1-5 \mathrm{~kg} ?$ & & & & & & $x$ & 1 & 1 & & \\
\hline $6-15 \mathrm{~kg} ?$ & & & & & & $x$ & 1 & 2 & & \\
\hline$>15 \mathrm{~kg} ?$ & & & & & & $x$ & 1 & 3 & & \\
\hline
\end{tabular}

Multiplique o valor da opção escolhida pelo código PA ou FO

12) Nos seus deslocamentos cotidianos, qual (is) o(s) meio(s) de transporte que você mais utiliza? Ordene as opções apresentadas, em ordem decrescente de utilização. (Entregue ao entrevistado a folha de respostas I).

\begin{tabular}{|c|c|c|c|}
\hline eu não saio & ordem & $\begin{array}{c}\text { Pontos PA } \\
0\end{array}$ & Pontos FO \\
\hline carro & & 0 & 1 \\
\hline bicicleta & & 2 & 1 \\
\hline transporte coletivo & & 1 & 2 \\
\hline a pé & & 1 & 0 \\
\hline Total $\Rightarrow$ & & & \\
\hline
\end{tabular}

Total de Pontos =soma das duas primeiras opções mencionadas em ordem decrescente.

\begin{tabular}{|c|c|}
\hline$\sum$ Pontos (II) PA $=$ & $\sum$ Pontos (II) FO $=$ \\
\hline TOT II (PA) $=\sum$ Pontos (II) PA / $71=$ & TOT II (FO) $=\sum$ Pontos (II) FO / $71=$ \\
\hline
\end{tabular}

\section{Parte III - O que o entrevistado deseja fazer}

13) Suas condições atuais de saúde e/ou físicas representam incômodo (ou impedimento) durante a execução de atividades cotidianas, associadas às situações mencionadas nesta lista? Em que grau você classificaria este incômodo? Se a situação mencionada não faz parte de suas atividades, considere o incômodo como 'Muito Pequeno' (Entregue ao entrevistado a folha de respostas J ).

\begin{tabular}{|c|c|c|c|c|c|c|c|c|c|}
\hline \multicolumn{2}{|c|}{ SITUAÇÃO } & \multirow[t]{2}{*}{$\mathrm{b}(1)$} & \multirow[t]{2}{*}{$c(2)$} & \multirow[t]{2}{*}{$d(3)$} & \multirow[t]{2}{*}{ e (4) } & \multirow{2}{*}{$\begin{array}{c}\text { PA } \\
1\end{array}$} & \multirow{2}{*}{$\begin{array}{c}\text { FO } \\
1\end{array}$} & \multirow[t]{2}{*}{ Pontos PA } & Pontos FO \\
\hline & Lavar e/ou passar roupa & & & & & & & & \\
\hline c) & Deslocamentos em casa et/ou imediações & & & & & 2 & 1 & & \\
\hline e) & Cozinhar & & & & & 1 & 1 & & \\
\hline f) & Fazer reparações em casa & & & & & 2 & 2 & & \\
\hline g) & Praticar desportos & & & & & 2 & 2 & & \\
\hline j) & Fazer compras (supermercado etc.) & & & & & 1 & 2 & & \\
\hline k) & Trabalhar no jardim ou no quintal & & & & & 2 & 2 & & \\
\hline l) & Transportar pesos & & & & & 1 & 3 & & \\
\hline & Longas caminhadas a pé & & & & & 3 & 1 & & \\
\hline n) & Outra: & & & & & & & & \\
\hline Mul & Itiplique o algarismo entre parêntesis pelo código PA ou FO. & & & $\sum T o t$ & $\Rightarrow$ & & & & \\
\hline
\end{tabular}

14a) Há alguma (s) atividade (s) que você fazia habitualmente e que gostaria de retomar, ou atividades que você gostaria de começar e não o faz? (Se o entrevistado é aposentado, evite considerar sua antiga atividade profissional):

Atividades: 
14b) Em relação à questão anterior, examine as proposições que apresentamos. Qual a afirmativa que definiria da melhor maneira (ou que se aproximaria mais de) seus sentimentos quanto às atividades que você mencionou? (Entregue ao entrevistado a folha de respos$\operatorname{tas} K)$ :

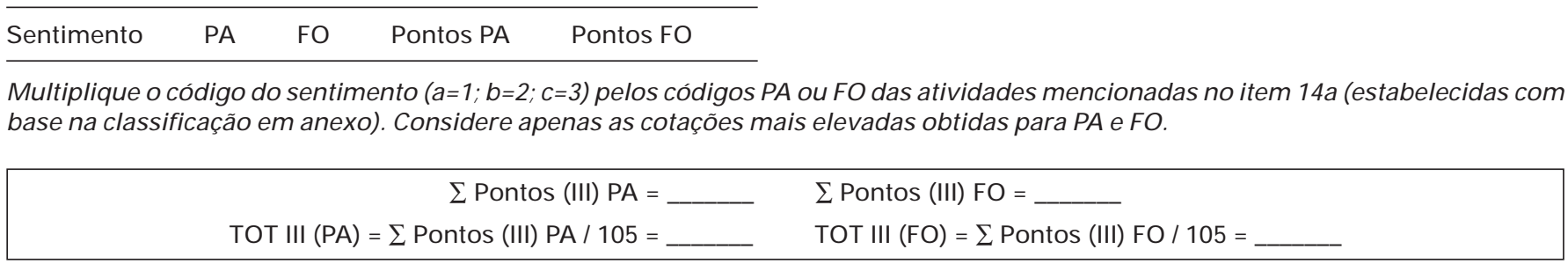

\section{Parte IV - Ponto de vista do entrevistador}

Esta parte do questionário deve ser preenchida pelo entrevistador, a partir de seus conhecimentos a respeito das características do ambientais e sociais da cidade, região, país etc. em que vive o entrevistado. Este julgamento deve ser independente das opiniões do entrevistado.

15) Como você classificaria o nível de esforço físico exigido pelo cotidiano do entrevistado? Considere aspectos como o local onde vive, a disponibilidade de transporte, sua atividade profissional e suas obrigações em geral.

\begin{tabular}{cccccccccc}
\hline muito leve & leve & médio & pesado & muito pesado & & PA & FO & Pontos PA & Pontos PO \\
0 & 1 & 2 & 3 & 4 & $\times$ & 1 & 1 & \\
\hline
\end{tabular}

Multiplique o valor da opção escolhida pelo código PA ou FO

16) Classifique o estresse térmico (temperatura elevada) ao qual o entrevistado se expõe durante suas atividades cotidianas:

\begin{tabular}{cccccccccc}
\hline muito leve & leve & médio & pesado & muito pesado & & PA & FO & Pontos PA & Pontos PO \\
0 & 1 & 2 & 3 & 4 & $\times$ & 1 & 1 & \\
\hline
\end{tabular}

Multiplique o valor da opção escolhida pelo código PA ou FO

17) De uma forma geral, classifique as necessidades, em termos de força de membros superiores e de capacidade cardiorrespiratória, (potência aeróbia), para que o entrevistado possa executar sem problemas suas atividades cotidianas, profissionais e de lazer, sem esquecer as atividades que ele gostaria de fazer e que, por uma razão ou outra, não faz (Muito Reduzidas, Reduzidas, Moderadas, Elevadas, Muito Elevadas):

PONTOS POTËNCIA AERÓBIA

$$
M R(0) \quad R E(1) \quad M O(2) \quad E(3) \quad M E(4)
$$

PONTOS FORÇA

Considere os algarismos entre parêntesis como o número de pontos para PA e FO.

$$
\begin{aligned}
\sum \text { Pontos (IV) PA }=\_ & \sum \text { Pontos (IV) FO }= \\
\text { TOT IV (PA) }=\sum \text { Pontos (IV) PA / } 12= & \text { TOT IV (FO) }=\sum \text { Pontos (IV) FO } / 12=
\end{aligned}
$$

\begin{tabular}{|c|c|c|c|c|c|c|c|c|c|c|c|}
\hline $\begin{array}{c}\text { ESCORES } \\
\text { PA } \\
\text { FO }\end{array}$ & TOT I & $\begin{array}{l}+ \\
+ \\
+\end{array}$ & TOT II & $\begin{array}{l}+ \\
+ \\
+\end{array}$ & TOT III & $\begin{array}{l}+ \\
+ \\
+\end{array}$ & TOT IV & $\begin{array}{l}1 \\
1 \\
1\end{array}$ & $\begin{array}{l}4 \\
4 \\
4\end{array}$ & $\begin{array}{l}= \\
= \\
=\end{array}$ & ITOT \\
\hline
\end{tabular}

\section{CLASSIFICAÇÃO GERAL}

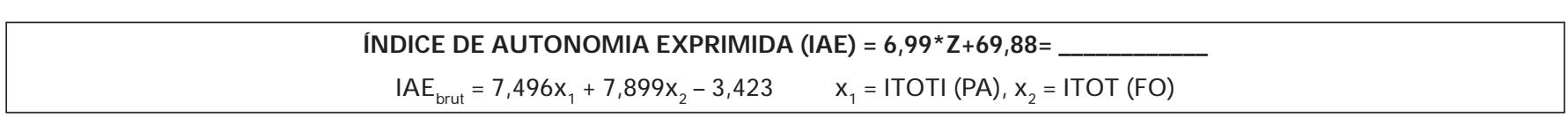

HORA DO FIM DA ENTREVISTA:

HR: MIN

ENTREVISTADOR: 


\section{NORMAS PARA ATRIBUIÇÃO DOS CÓDIGOS PA E FO}

\section{1) Produção de energia para o trabalho (PA)}

Grau 0) Atividades sedentárias, que não requerem adaptação cardiorrespiratória em níveis muito diferentes da atividade de repouso. Trata-se das atividades que se realizam sentado durante a maior parte do tempo, como ler, escrever etc. Em termos de gasto calórico, poderíamos atribuir o grau 0 às atividades que se situam entre 1 e 2 METs. Como exemplos, temos as atividades burocráticas de forma geral e a grande maioria das profissões liberais (advogados, médicos etc.).

Grau 1) Atividades muito leves, mas que requerem certa adaptação do sistema cardiorrespiratório (freqüência cardíaca, respiração etc.). O gasto calórico associado a essas atividades é de 2 a 4 METs. Boa parte das atividades de lazer situa-se nessa faixa, como os passeios de bicicleta $(<15 \mathrm{~km} / \mathrm{h})$, os passeios a pé $(<5 \mathrm{~km} / \mathrm{h})$, brincar com crianças. Normalmente, tratam-se de atividades que se pode realizar de forma contínua, durante longos períodos, sem interrupções constantes.

Grau 2) São atividades cuja intensidade exige adaptação importante do sistema cardiorrespiratório. Para uma pessoa sedentária, as interrupções fazem-se mais constantes, e constata-se marcada elevação da freqüência cardíaca e do ritmo respiratório. Muitas vezes essas atividades ultrapassam o limite de execução confortável. Seu gasto calórico é da ordem de 4 a 6 METs. Alguns exemplos: ciclismo entre 15 e $20 \mathrm{~km} / \mathrm{h}$, marcha acelerada (mais do que $5 \mathrm{~km} / \mathrm{h}$ ), carregar pesos de cerca de 10-12kg, dança aeróbia de baixo impacto, trabaIhos de carpintaria, jardinagem, mudanças (móveis etc.) ou faxina pesada.

Grau 3) Atividades pesadas, cuja intensidade pede adaptação muito importante do sistema cardiorrespiratório. As interrupções são constantes, a freqüência cardíaca pode ser considerada alta, a pessoa hiperventila. O nível de sudação, em climas quentes e úmidos, é igualmente importante. Essas atividades têm gasto calórico superior a 6 METs. Como exemplos citamos os desportos coletivos e/ou competitivos de forma geral, as atividades para as quais um treinamento prévio é por vezes necessário (trekking, alpinismo, mergulho em profundidade etc.) e atividades profissionais que dependem fundamentalmente de boa condição física (trabalhar a terra, caminhar durante horas, subir longos lances de escada etc.).

\section{2) Força de membros superiores (FO)}

Grau 0) Atividades durante as quais não há aplicação de força de membros superiores. As mãos estão completamente livres, e o peso do corpo não é sustentado pelos braços em nenhuma ocasião.

Grau 1) As atividades aqui classificadas associam-se à elevação e/ou transporte de pesos de até $5 \mathrm{~kg}$. Essa intensidade pode ser considerada muito leve, mas estas cargas situam-se em torno do limiar de $30 \%$ da força máxima de preensão manual em muitos sujeitos, o que restringe a duração da aplicação da força. Pode-se classificar ainda nesta categoria cargas ligeiramente superiores ao limite de $5 \mathrm{~kg}$, mas cuja duração é muito reduzida.

Grau 2) Refere-se às cargas situadas entre 5 e 15kg, ou equivalentes. A intensidade aqui é de moderada a elevada, aproximando-se dos $50-60 \%$ da força máxima em muitos indivíduos de mais de 60 anos. A duração da aplicação da força tende ser curta, e intervalos são constantemente adotados durante as tarefas que requerem tal esforço. A duração das atividades desempenha um papel importante na atribuição dos graus para a força. Assim, cargas limítrofes (em torno de 5kg) podem ser encaixadas aqui, se o período de execução da tarefa é muito longo.

Grau 3) Atividades que requerem uma aplicação de força superior a $15 \mathrm{~kg}$ (mais de $60 \%$ da força máxima das mãos). Nestas atividades as interrupções são praticamente obrigatórias, a aplicação da força se dá durante breves períodos. Temos aqui, por exemplo, as atividades em que se sustenta boa parte do peso corporal (como alpinismo), ou para as quais a explosão muscular é importante (remo). No campo profissional, todas as atividades calcadas no transporte de cargas. As recomendações quanto ao tempo de aplicação da força são as mesmas que para o item anterior: assim, dependendo da situação, pesos de $10 \mathrm{~kg}$ poderiam ser classificados como $\mathrm{FO}=3$. Bastaria para tanto que, durante a atividade em questão, essa carga devesse ser obrigatoriamente sustentada durante longos períodos de tempo. 


\section{QUESTIONÁRIO SENIOR}

Folha de respostas A
Freqüência: a) Menos que uma vez por semana
b) 1 a 2 vezes por semana
c) 3 a 4 vezes por semana
d) Mais do que 4 vezes por semana
e) Não faço jamais esta atividade
Duração
a) Menos que 10 minutos
b) De 10 a 30 minutos
c) De 30 a 60 minutos
d) Mais do que 60 minutos

\section{ATIVIDADE}

1) Faxina leve (varrer, aspirar, tirar a poeira, passar a ferro etc.)

2) Faxina pesada (muros e janelas, mudar móveis de lugar etc.)

3) Lavar a louça

4) Cozinhar

5) Transportar cargas pesadas (sem subir escadas)

6) Transportar cargas pesadas (subindo escadas)

7) Fazer compras (supermercado, shopping etc.)

8) Trabalhar no jardim ou no quintal

9) Lava a roupa (manualmente)

10) Fazer reparações leves (trocar lâmpadas, consertar torneiras etc.)

11) Fazer reparações pesadas (pintar paredes, carpintaria, serralheria etc.)

12) Brincar e/ou ocupar-se de crianças

13) Ocupar-se de pessoa idosa ou doente (lavar, vestir etc.)

14) Outra:

\section{QUESTIONÁRIO SENIOR \\ Folha de respostas $B$}

\section{APOSENTADO (Ano):}

\section{TRABALHO SEDENTÁRIO}

Todas as atividades cuja intensidade de esforço é mínima, durante as quais se fica sentado a maior parte do tempo, ou cujas exigências de deslocamento limitam-se à área do escritório, laboratório etc.
Administrativo (empregados de escritório)

Condutor (carro, ônibus, trem etc.)

Escritor

Prof. liberais (médicos, advogados, professores etc.)

Secretário

Alfaiate, costureiro etc.

\section{TRABALHO LEVE}

Todas as atividades que requerem nível de esforço razoável, mas cuja importância não resida nem em transporte manual de pesos, nem na aplicação contínua e intensa de força muscular. O indivíduo não sente uma aceleração marcada da respiração ou da freqüência cardíaca, nem uma transpiração abundante.
Padeiro

Carpinteiro

Guarda de trânsito (urbano)

Sapateiro

Cozinheiro

Enfermeiro

Mecânico
Serralheiro

Faxineiro

Operador de máquinas pesadas (indus-

triais ou domésticas)

Encanador

Servente

Camareiro

Vigilantes (guarda noturno etc.) 
Todas as atividades para as quais boa condição física é essencial, e que requerem pausas freqüentes de repouso. Atividades que induzem respiração e batimentos cardíacos acelerados, e que provocam transpiração abundante. Atividades que exigem longos deslocamentos a pé, corridas ou aplicação contínua de grande força muscular. Enfim, as atividades baseadas no vigor e na resistência físicas.

Freqüência:

a) Até 2 vezes por semana

b) De 2 a 3 vezes por semana

c) De 3 a 4 vezes por semana

d) Mais do que 4 vezes por semana
Agricultor (trabalhador da terra)

Gari

Lenhador

Estivador

Carteiro

Pedreiro

Mineiro

Pescador

Bombeiro

Carregador (mudanças, demolição etc.)

Duração

a) Até 2 horas por dia

b) De 2 a 4 horas por dia

c) De 4 a 6 horas por dia

d) Mais do que 6 horas por dia

\section{QUESTIONÁRIO SENIOR}

Folha de resposta C

\begin{tabular}{|lc|}
\hline Alongamento & $1-1$ \\
Alpinismo/trekking & $3-3$ \\
Badminton & $2-2$ \\
Basquetebol & $3-2$ \\
Bilhar & $0-1$ \\
Boliche & $1-2$ \\
Caça & $1-2$ \\
Caminhada (passeio) & $1-0$ \\
Caminhada (marcha acelerada) & $2-0$ \\
Ciclismo (passeio) & $2-1$ \\
Ciclismo (velocidade, competição) & $3-2$ \\
Ciclismo (mountain-bike) & $3-3$ \\
Dança & $2-1$ \\
Escultura & $1-2$ \\
Esqui (fundo) & $3-2$ \\
Esqui (montanha) & $2-3$ \\
Escutar música & $0-0$ \\
Futebol (salão e campo) & $3-1$ \\
Golfe & $1-2$ \\
Ginástica (calistenia, tradicional) & $2-1$ \\
Ginástica aérobia (high-impact) & $3-1$ \\
Ginástica aérobia (low-impact) & $2-1$ \\
Handebol & $3-2$ \\
\hline
\end{tabular}

\section{Freqüência: a) Nenhuma ou menos do que uma vez por} semana

b) 1 a 2 vezes por semana

c) 3 a 4 vezes por semana

d) Mais do que 4 vezes por semana

$\begin{array}{lr}\text { Hidroginástica } & 2-1 \\ \text { loga } & 1-1 \\ \text { J ardinagem } & 2-2 \\ \text { J ogging (corrida a pé) } & 3-0 \\ \text { J ogar cartas } & 0-0 \\ \text { Ler } & 0-0 \\ \text { Lutas (judô, jiu-jitsu, caratê, capoeira etc.) } & 2-3 \\ \text { Musculação } & 1-3 \\ \text { Natação } & 3-1 \\ \text { Pintura (quadros) } & 0-1 \\ \text { Pintura (paredes) } & 1-2 \\ \text { Patinagem } & 2-0 \\ \text { Pesca } & 1-2 \\ \text { Petanca/bocha } & 1-1 \\ \text { Remo } & 3-3 \\ \text { Squash } & 3-2 \\ \text { Tocar instrumentos musicais } & 0-1 \\ \text { Tênis } & 3-2 \\ \text { Tiro (arco, armas de fogo etc.) } & 1-1 \\ \text { Trabalhos manuais (mecânica, serralheria etc.) } & 1-3 \\ \text { Volibol, netvôlei (sala) } & 2-2 \\ \text { Volibol (praia) } & 3-2 \\ \text { Xadrez/jogo de damas } & 0-0\end{array}$

Duração 


\section{QUESTIONÁRIO SENIOR}

Folha de respostas D
a) Nenhum
b) De 1 a 5 lances por dia
c) De 6 a 10 lances por dia
d) De 10 a 15 lances por dia
e) Mais de 15 lances por dia

\section{QUESTIONÁRIO SENIOR \\ Folha de respostas $E$}

a) Menos do que 5 minutos

b) De 5 a 10 minutos

c) De 10 a 15 minutos

d) De 15 a 20 minutos

e) Mais do que 20 minutos

\section{QUESTIONÁRIO SENIOR}

Folha de respostas $F$
a) Muito bom
b) Bom
c) Razoável
d) Ruim
e) Muito ruim

\section{QUESTIONÁRIO SENIOR \\ Folha de respostas $\mathbf{G}$}
1) Muito leve:
trabalho sentado (dirigir, ler, bater à máquina etc.).
2) Leve:
trabalho em pé com atividade muscular redu- zida (vendedores etc.).
3) Médio:
atividade muscular de intensidade moderada (lavar roupa manualmente, carregar pesos de menos de $5 \mathrm{~kg}$, faxinar, etc.).

4) Pesado:

atividade muscular intensa, respiração e coração acelerados, transpiração moderada (varrer ruas, trabalho de manutenção mecânica, jardinagem pesada, longas caminhadas etc.).

5) Muito pesado: atividade muscular de grande intensidade, respiração e coração acelerados, transpiração abundante (cortar lenha, cavar a terra, carregar pesos de mais de $15 \mathrm{~kg}$, etc.).

\section{QUESTIONÁRIO SENIOR}

Folha de respostas $\mathrm{H}$
a) J amais
b) Muito raramente
c) Raramente
d) Freqüentemente
e) Quase todo o tempo

\section{QUESTIONÁRIO SENIOR \\ Folha de respostas I}

Mencione, em ordem decrescente (do meio de transporte mais utilizado ao menos utilizado), as opções seguintes:

a) Eu não saio de casa

b) carro ou táxi

c) bicicleta

d) transportes coletivos (ônibus, metrô, bonde, trem), exceto táxi e) a pé

\section{QUESTIONÁRIO SENIOR Folha de respostas J}

a) Meu estado físico representa um incômodo/impedimento MUITO PEQUENO para minhas atividades.

b) Meu estado físico representa um incômodo/impedimento PEQUENO para minhas atividades.

c) Meu estado físico representa um incômodo/impedimento MODERADO para minhas atividades.

d) Meu estado físico representa um incômodo/impedimento GRANDE para minhas atividades.

e) Meu estado físico representa um incômodo/impedimento MUITO GRANDE para minhas atividades.

\section{SITUAÇÃO}

1) Lavar e/ou passar roupa

2) Utilização dos transportes coletivos

3) Deslocamentos em casa et/ou imediações

4) Subir e descer escadas

5) Cozinhar

6) Fazer reparações em casa

7) Praticar desportos

8) Ver/visitar os amigos

9) Limpar, fazer faxina

10) Fazer compras (supermercado etc.)

11) Trabalhar no jardim ou no quintal

12) Transportar pesos

13) Longas caminhadas a pé

14) Outra:

\section{QUESTIONÁRIO SENIOR Folha de respostas $K$}

a) O fato de não fazer essas atividades não afeta minha qualidade de vida. Não tenho sentimentos negativos quanto a essa situação. A interrupção dessas atividades (ou o fato de não poder começá-las) é algo que considero parte de minha evolução como pessoa, um fenômeno normal da vida.

b) Sinto-me verdadeiramente triste de ter interrompido essas atividades, ou de não poder começá-las. Minhas condições de vida (saúde, tempo, família etc.) impedem-me, mas gostaria realmente de continuá-las, retomá-las ou começá-las. Isso seria um aspecto importante do meu bem-estar, de minha realização pessoal.

c) O fato de não fazer essas atividades é realmente duro. Minha qualidade de vida é francamente afetada e sinto-me revoltado e zangado de não praticá-las. Faria tudo para que assim não fosse, pois essas atividades representam uma parte importante de minha vida. A impossibilidade de continuá-las, retomálas ou começá-las representa uma limitação importante de meu bem-estar e de minha autonomia individual. 